\title{
Young men and masculinities in Japanese media: (Un-)conscious Hegemony, Ronald Saladin
}

Edition 2, 2020

Michaela Luschmann

DOI: 10.37839/MAR2652-550X2.16

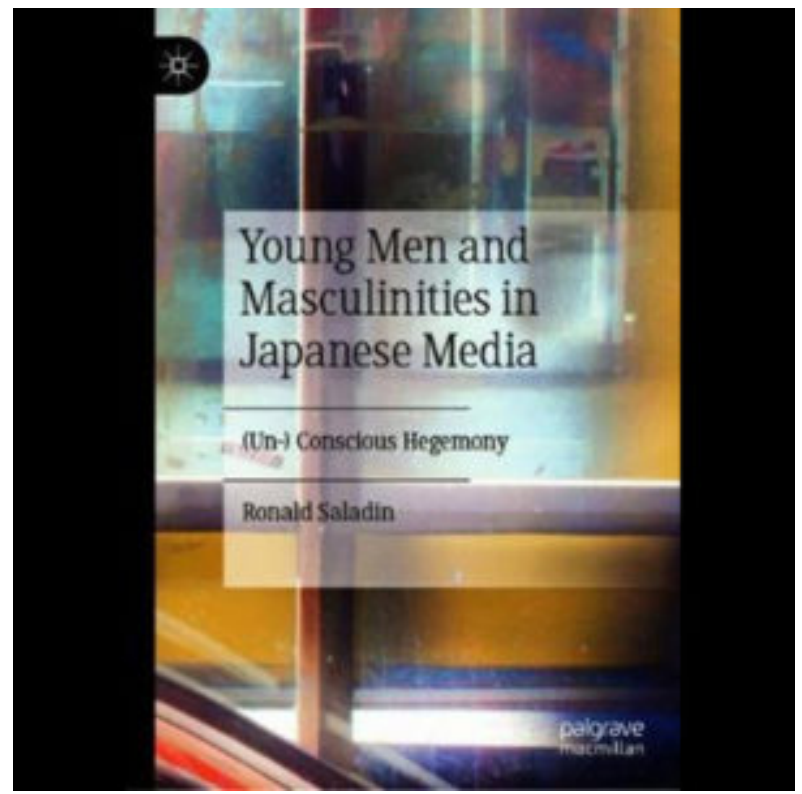

Print magazines have been a staple of Japanese households since the 1980s, when women's magazines gained a great deal of popularity and many new titles were published. Even though men's tastes and preferences have been prioritised in the production of all Japanese magazines not explicitly aimed at women, magazines that specifically highlight fashion and lifestyle for men experienced a boom in the 1990s. Japan continues to have a strong market for print media of which popular publications such as men's magazines are an integral part.

Author Ronald Saladin explores representations of masculinity in two Japanese 
men's magazines published from the 1990s to the 2000s with the aim of revealing which constructions of masculinity are conveyed and how the existing gender order is (re)produced.

His investigation revolves around the idea that magazines are a tool that enables young people to connect by informing them about fashion and lifestyle trends; thereby serving as a means of creating identity. Magazines are regarded as cultural artifacts that convey constructions of gender and identity in the form of male and female types within Japanese youth cultures. The readers are not just passive recipients of these messages, but are also involved in the production process by modelling fashion trends in published features and giving interviews about their lifestyle and relationships.

Saladin concentrates his analysis on two typical magazines for young men ChokiChoki and Men's Egg. The ways in which gender is constructed in these magazines is mainly evaluated through the patterns that emerge in how the 'ideal' man is represented in articles and comics, especially in comparison with how women are positioned. Whether women are portrayed as having a voice or not, are active or passive, being served or are of service; the way women are represented clearly shows the role assigned to men in the magazines.

ChokiChoki's target audience can be described as the so-called 'herbivore men' (sōshokukei danshi), Saladin writes. These men represent a 'soft masculinity' and are described as having adopted certain behaviours that were traditionally considered feminine, such as using cosmetics or taking care of one's appearance, and who are shy or generally disinterested in romantic relationships and sex.

Men's Egg targets the gyaru-o, men who are part of the gyaru youth culture. This subculture developed in the 1990s, when a specific fashion style was established by high school girls in Tokyo's Shibuya district wearing heavy make-up, tanned skin, and sexy clothing. The gyaru-o are the male counterpart of the gyaru (from the English world 'girl') who also wear flashy attire which includes tanned skin and 
specific hairstyles with voluminous, teased, and coloured hair and tattoos.

While the types of men that are depicted in both magazines display traits that were considered feminine in previous generations, Saladin discovers that they do not display a completely new ideal image of how a man should be. In both cases, the representations are still close to the form of masculinity that maintains the gender order, called the 'hegemonic masculinity'.

Being 'charai' in Men's Egg (being able to attract, seduce and satisfy women through good looks, physical fitness and charm) is emphasised as the masculine ideal. Similarly, even though the readers of ChokiChoki are 'soft men', women are depicted as a prize that must be won through competition between men; or they are depicted as experts of household tasks. Additionally, non-heterosexual preferences are not depicted as an option and homophobic messages demonstrate the heteronormative ideology constructed in the magazine.

Saladin argues that instead of moving away from patriarchal ideals of how a man should be, the established gender order is maintained by men's magazines, albeit allowing for some change in socially-acceptable behaviour, including caring about one's appearance and showing emotion to their female partners. He concludes that both magazines construct a hybrid form of masculinity which retains in its core of 'hegemonic masculinity' - that which ultimately reproduces a gender order that assigns the most powerful position in society to a certain group of men.

Saladin's book provides fascinating insights into the world of Japanese magazine production, Japanese youth culture and the gendered dimension of men's fashion and lifestyle magazines. His book is an important addition to existing research into media representations of masculinity in a Japanese cultural context and highly relevant to those interested in Japanese print media.

Banner image: MIKI Yoshihito/Flickr. Image of book cover provided by the book's author. 